CZU: 664.8

https://doi.org/10.53082/1857-3142.21.85.03

\section{Sporirea valorii nutritive a băuturilor de fructe prin fortificare cu micro- şi macroelemente}

Elena PÎRGARI,

https://orcid.org/0000-0002-4912-2397;

email: elenapirgaru@mail.ru;

Svetlana POPEL, doctor în științe tehnice,

https://orcid.org/0000-0002-4575-5920;

email: sspopeli@mail.ru;

Lidia PARŞACOVA,

https://orcid.org/0000-0002-8232-9656;

email:j-eml@rambler.ru;

Alexandra COLESNICENCO,

https://orcid.org/0000-0001-8395-1829;

Elena DRAGANOVA,

https://orcid.org/0000-0002-6213-7112;

Elena ZîREANOVA,

https://orcid.org/0000-0002-7625-175X;

\section{Larisa VîCEROVA,}

https://orcid.org/0000-0001-6267-7453;

email: loravicerova@inbox.ru

Institutul Ştiinţifico-Practic de Horticultură şi Tehnologii Alimentare

Rezumat. în lucrare s-a argumentat necesitatea fortificării băuturilor de fructe cu micro- şi macroelemente. S-au selectat cei mai potriviti compuşi ai fierului şi ai calciului pentru fortificare, tipul băuturilor şi s-au argumentat ştiinţific dozele introducerii acidului ascorbic necesare pentru asimilarea fierului. S-a demonstrat necesitatea alegerii tipului de băuturi pentru fortificare în funcție de gradul de limpezire şi selectarea compuşilor macro- şi microelementelor după compatibilitatea cu compoziţia băuturilor. Sunt prezentate rezultatele determinării caracteristicilor organoleptice şi fizico-chimice ale băuturilor fortificate în scopul stabilirii termenului de valabilitate.

Cuvinte-cheie: băutură fortificată, microelemente, vitamine, doza recomandată, grad de integritate.

Abstract. The article argued the necessity to fortify fruit drinks with micro- and macroelements. Were scientifically argued the most suitable compounds for fortification - iron and calcium, were selected the type of beverage, and the doses of the introduction of ascorbic acid required for the assimilation of iron. Was demonstrated the necessity to choose the type of fortification drinks according to the degree of clarification and the selection of macro compounds and microelements according to the compatibility with the composition of the drinks. The results of the determinations of the organoleptic and physicochemical characteristics of the fortified drinks are presented in order to establish the expiration date.

Keywords: beverage fortified, microelements, vitamins, recommended dose, degree of integrity.

\section{INTRODUCERE}

Savanţii din toată lumea remarcă că unul dintre cei mai importanţi factori care determină starea sănătăţii şi gradul capacităţii de muncă a populaţiei este integritatea biologică şi inofensivitatea alimentaţiei, iar medicina constată că sănătatea omului depinde la nivel de $50-60 \%$ de calitatea nutriţiei. În opinia savanţilor, alimentaţia sănătoasă trebuie examinată sub mai multe aspecte, inclusiv economic, fiziologic şi informaţional.

Aspectul economic presupune accesibilitatea produselor „alimentaţiei sănătoase” pentru toate păturile sociale ale populaţiei în conformitate cu necesităţile fiziologice, gusturile şi tradiţiile. Sortimentul produselor „alimentaţiei sănătoase” nu poate fi limitat numai la produse „organice" sau „ecologic pure”, care, fiind costisitoare, nu sunt accesibile pentru un consum larg.

Aspectul fiziologic este cel mai important în evaluarea caracteristicilor alimentaţiei sănătoase. Nivelul alimentaţiei sănătoase este determinat de sortimentul produselor, valoarea lor biologică şi nutritivă, prezenţa micro- şi macrocomponentelor. Un produs alimentar nu poate fi examinat în exclusivitate numai din punctul de vedere al valorii energetice (calorice). Alimentele sănătoase trebuie să fie echilibrate după conţinutul de substanţe alimentare necesare pentru funcţionarea organismului.

În ultimele decenii, în legătură cu modificarea condiţiilor de muncă şi de trai ale populaţiei s-a redus necesitatea în energie şi, ca urmare, cheltuielile energetice diurne s-au micşorat considerabil, constituind 2600-3 $000 \mathrm{kcal}$. Produsele cu o astfel de valoare energetică nu pot conţine cantitatea necesară de vitamine, minerale, aminoacizi şi alte substanţe esenţiale pentru funcţionarea normală a organismului.

Pe lângă aceasta, tehnologiile alimentare contemporane sunt direcţionate spre obţinerea produselor $\mathrm{cu}$ un grad înalt de purificare, care nu conţin multe substanţe utile organismului.

Aceasta a impulsionat apariţia unei direcţii noi în industria alimentară, şi anume fabricarea produselor alimentare funcţionale ca parte componentă a alimentaţiei sănătoase.

Un produs alimentar poate deveni funcţional prin fortificarea lui, modificarea componentelor naturale ale produsului sau eliminarea componentelor nedorite.

Cele mai deficitare în alimentaţie sunt:

- vitaminele grupei $B$, vitamina $A, D, P P$, acidul folic;

- antioxidanţii: vitamina C, E, carotenoizii;

- macroelementele: calciul, caliul, magneziul;

- microelementele: iodul, fierul, seleniul, zincul, fluorul;

- aminoacizii de neînlocuit;

- acizii graşi nesaturaţi: $\omega_{3}$ şi $\omega_{6}$;

- fibrele alimentare.

În prezent se caută surse noi de substanţe esenţiale, netradiţionale şi se elaborează direcţii noi în teh- 
nologia fabricării produselor tradiţionale care posedă proprietăţi funcţionale.

Piaţa mondială a produselor funcţionale se dezvoltă intens, crescând anual cu 15-20\%. În volum de 95\% aparţine SUA, Japoniei, ţărilor Europei Centrale, locurile de frunte revenindu-le Germaniei, Marii Britanii, Franţei.

În ţările menţionate, de cea mai mare popularitate se bucură băuturile fortificate cu vitamine, macro- şi microelemente.

Strategia şi practica creării produselor alimentaţiei sănătoase cu utilizarea macro- şi microingredientelor include aspecte medico-biologice, aspectul tehnologic şi eficacitatea clinică.

Reieşind din integritatea micronutrientului introdus, compatibilitatea micronutrientului cu produsul, interacţiunea cu alte componente ale produsului alimentar, asimilarea biologică a componentului fortificant, eficienţa corecţiei deficitului şi ameliorarea sănătăţii în urma utilizării produsului fortificat, băuturile reprezintă obiectul cel mai potrivit pentru fortificarea cu micro- şi macroelemente şi vitamine solubile în apă.

Este dovedit ştiinţific că substanţele minerale şi vitaminele se asimilează mai bine şi mai complet din produsele alimentare lichide, unde posibilitatea interacţiunii chimice a micronutrienţilor între ei şi cu componentele produsului supus fortificării este minimă.

Pentru îmbogăţirea raţiei alimentare cu macro- şi micronutriente, componente minore ale alimentelor, cel mai mult se potrivesc băuturile. Aceasta se datorează faptului că băuturile sunt produse de larg consum şi asimilarea substanţelor nutritive este mai eficientă în timpul consumului de băuturi, decât al unor alimente consistente. Din punctul de vedere al tehnologiei, băuturile prezintă cel mai tehnologic obiect pentru fortificare, deoarece introducerea majorităţii ingredientelor funcţionale în băuturi nu înrăutăţeşte procesul tehnologic.

\section{MATERIALE SI METODE DE CERCETARE}

2.1. Alegerea sortimentului de produse şi elaborarea reţetelor băuturilor pe bază de sucuri şi a piureurilor pentru fortificarea acestora

Reieşind din Programele de Stat aprobate în Republica Moldova privind iradicarea anumitor maladii [1, 2], studierea literaturii tehnico-ştiinţifice şi a experienţei mondiale, a fost luată decizia de a fortifica băuturile: I lot - cu fier şi vitamina C şi al II-lea lot - cu calciu.

Pe piaţa Europei de Est există un şir de produse pentru alimentaţia maturilor, copiilor, inclusiv a sugarilor începând de la vârsta de 5 luni, cum ar fi piureurile „Agu-Agu”, „Gherber”, „Nestle”, „FruktoNeanea”, "Krepîş” ş.a., fortificate cu vitamina C, cu prebiotice şi vitamina $C$, sucuri pentru copii şi maturi, inclusiv pentru femeile gravide şi femeile care alăptează, cu conţinut de fier, vitaminele grupei B, vitamina $\mathrm{C}$, acid folic, vitamina $\mathrm{E}$, calciu.

Majoritatea piureurilor produse peste hotarele ţării sunt policomponente şi le includ pe cele de mere, morcov, dovleac, dovlecei, coacăză-neagră, coacăzăroşie, vişine, căpşune, pere, piersice ş.a.

Sucurile se fabrică pe bază de sucuri de mere, morcov, piersice, vişine, dovleac, răchiţele, căpşune, fructe tropicale: ananas, portocale, mango ş.a.

În conformitate cu Reglementarea Tehnică a Republicii Moldova „Sucuri şi anumite produse similare destinate consumului uman" [3] şi Standardul Moldovenesc 168 „Băuturi de fructe şi pomuşoare” [4], sucurile, nectarele şi băuturile se fabrică:

- în funcţie de tehnologie: fără miez (nelimpezite şi limpezite) şi cu miez;

- în funcţie de materia primă utilizată: monocomponente şi cupajate.

Băuturile pe bază de sucuri şi piureuri de fructe şi pomuşoare au fost selectate reieşind din următoarele criterii:

- sunt produse de larg consum;

- reprezintă obiectul cel mai tehnologic din punctul de vedere al introducerii fortificantului;

- este dovedit ştiinţific că asimilarea substanţelor minerale şi vitaminelor este cea mai înaltă anume din produsele lichide;

- fortificanţii pot fi introduşi atât sub formă de pulbere (uscată), cât şi sub formă de substanţe lichide;

- compoziţia băuturilor poate fi aleasă în aşa mod, încât să asigure compatibilitatea produsului nativ cu fortificantul introdus, precum şi asimilarea acestuia prin prezenţa anumitor vitamine, substanţe minerale, fibre alimentare, care contribuie la asimilarea lor.

Există un şir de cercetări, pe plan mondial, care dovedesc că pentru o bună asimilare a fierului este necesară prezenţa vitaminei $\mathrm{C}$, acidului folic, manganului, cuprului, iar calciul se asimilează în prezenţa fibrelor alimentare.

Pentru fortificare au fost selectate două tipuri de băuturi:

1. Băutura în bază de sucuri de fructe, limpezită, pentru fortificare cu fier şi vitamina $C$.

2. Băutura în bază de piureuri de fructe, cu miez, pentru fortificare cu calciu (întrucât conţine fibre alimentare).

Băuturile în bază de fructe şi pomuşoare autohtone: mere, vişine, caise, piersice, coacăză-neagră, sunt accesibile pentru producători din punctul de vedere al materiei prime şi sunt tolerate practic de toţi consumatorii, în comparaţie cu băuturile din materia primă de import: portocale, mango, papaia, ananas.

\subsection{Selectarea celor mai potriviți compuşi} ai calciului şi ai fierului pentru fortificarea produselor sub formă lichidă şi dozele lor

Selectarea compuşilor calciului, fierului şi vitaminei C s-a efectuat reieşind din compuşii recomandaţi pentru utilizare şi prezentaţi în „Regulamentul sanitar pri- 
vind suplimentele alimentare" aprobate pentru utilizare prin Hotărârea Guvernului Republicii Moldova nr. 538 din 02.09.2009 [5].

Vitamina C s-a selectat din şirul următorilor compuşi: acid L-ascorbic, L-ascorbat de sodiu, L-ascorbat de calciu, L-ascorbat de potasiu, L-ascorbil 6-palmitat.

Compusul fierului s-a selectat din şirul următorilor compuşi: carbonat feros, citrat feros, citrat feric de amoniu, gluconat feros, fumarat feros, difosfat feric de sodiu, lactat feros, sulfat feros.

Compusul calciului s-a selectat din şirul următorilor compuşi: carbonat de calciu, clorură de calciu, săruri de calciu ale acidului citric, gluconat de calciu, glicerofosfat de calciu, lactat de calciu, săruri de calciu ale acidului ortofosforic, hidroxid de calciu, oxid de calciu.

Cantitatea de fier, calciu și vitamina $\mathrm{C}$ a fost calculată în aşa mod, încât produsul finit să conţină $15 \%$ din doza zilnică recomandată (DZR) de fier, $30 \%$ din DZR de vitamina C, $15 \%$ din DZR de calciu. Dozele zilnice recomandate pentru nutrimentele utilizate sunt prezentate în tabelul 1.

\section{Doza zilnică recomandată (DZR) de vitamine și minerale [5]}

\begin{tabular}{|l|c|c|}
\hline Denumirea & $\begin{array}{c}\text { Unitatea de } \\
\text { măsură }\end{array}$ & $\begin{array}{c}\text { Valoarea medie } \\
\text { a DZR }\end{array}$ \\
\hline Vitamina C & $\mathrm{mg}$ & 80 \\
\hline Calciu & $\mathrm{mg}$ & 800 \\
\hline Fier & $\mathrm{mg}$ & 14 \\
\hline
\end{tabular}

Pentru fortificarea băuturii limpezite, pe bază de sucuri de fructe, s-au utilizat:

- sulfatul de fier, $\mathrm{FeSO}_{4} \times 7 \mathrm{H}_{2} \mathrm{O}$, cu $20 \%$ de fier activ din conţinutul total de fier în preparat, întrucât este cel mai răspândit printre preparatele medicinale utilizate în tratamentul anemiilor, se asimilează mai bine comparativ cu alţi compuşi, este uşor solubil în lichide;

- vitamina C sub formă de acid L-ascorbic, deoarece dintre compuşii propuşi pentru fortificare conţine cel mai mare procent de acid ascorbic.

Pentru fortificarea băuturii nelimpezite, pe bază de piureuri de fructe în combinaţie cu sucuri de fructe, $s-a$ utilizat lactatul de calciu, $2\left(\mathrm{C}_{3} \mathrm{H}_{5} \mathrm{O}_{3}\right) \times \mathrm{Ca} \times 5 \mathrm{H}_{2} \mathrm{O}$, deoarece este un compus al calciului practic fără miros, se dizolvă bine în apă caldă, se asimilează uşor de organism, comparativ cu glicerofosfatul de calciu nu provoacă schimbarea gustului alimentelor, iar comparativ cu gluconatul de calciu conţine un procent mai mare de calciu.

2.3. Experimentarea tehnologiei de introducere a calciului, fierului şi a vitaminei $C$ în produse

Pentru fabricarea băuturilor cu conţinut garan- tat de vitamine şi minerale în produsul finit, stabil pe durata păstrării, s-a experimentat tehnologia de introducere a calciului, fierului şi vitaminei $C$ pe trei loturi:

1. Băutură de mere şi vişine limpezită în baza sucurilor limpezite fortificată cu fier şi vitamina C;

2. Băutură de mere şi caise nelimpezită în baza piureului de mere, piureului de caise şi a sucului de mere fortificată cu calciu (în prezenţa fibrelor alimentare native);

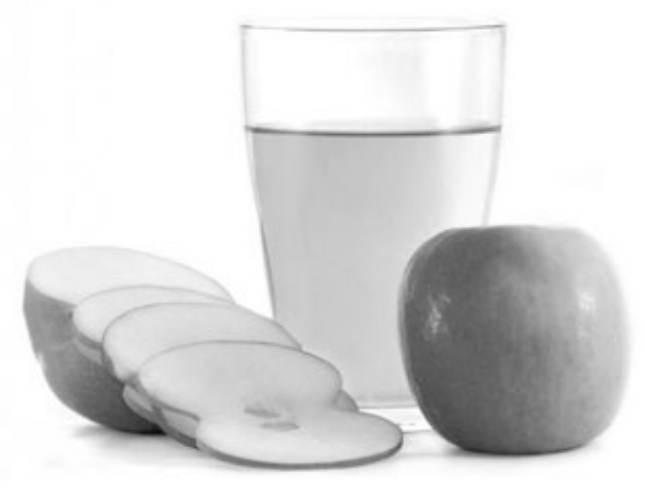

3. Băutură de mere limpezită în baza sucului de mere limpezit fortificată cu fier şi vitamina $C$.

Băutura de mere şi vişine limpezită în baza sucurilor limpezite a fost fortificată cu 2,1 mg de fier în $200 \mathrm{ml}$ de băutură, ceea ce constituie $15 \%$ din DZR (14 mg) şi cu vitamina C în cantitate de 30\% din DZR $(80 \mathrm{mg})$.

Băutura de mere şi caise nelimpezită în baza piureului de mere, a piureului de caise şi a sucului de mere a fost fortificată cu calciu în cantitate de 15\% din DZR (800 mg) în 200 ml de băutură.

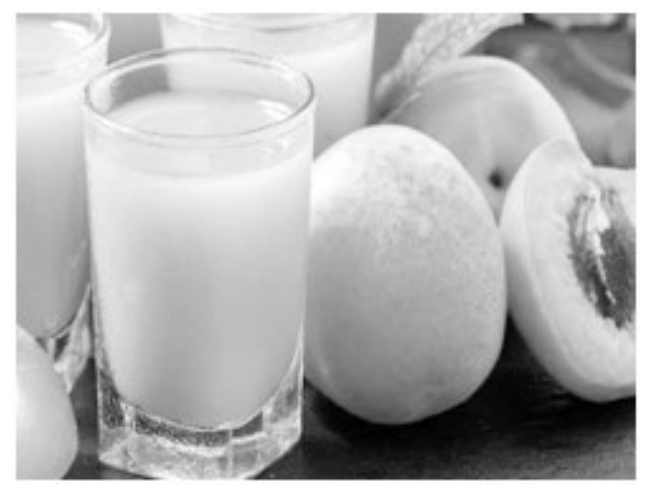

Băutura de mere limpezită în baza sucului de mere limpezit a fost fortificată cu fier în cantitate de $25 \%$ din DZR şi cu vitamina C în cantitate de 50\% din DZR.

Introducerea fortificanților s-a efectuat prin dizolvarea lor într-o cantitate mică de băutură luată din masa totală a băuturii pregătite înainte de sterilizare. Pentru a evita pierderile vitaminei $C$ în procesul de încălzire a băuturii până la temperatura de ambalare $\left(80^{\circ} \mathrm{C}\right)$, introducerea vitaminei $\mathrm{C}$ s-a efectuat nemijlocit înainte de turnarea băuturii în borcane, cu ime- 
Tabelul 2

Caracteristicile fizico-chimice ale băuturii de mere şi vişine limpezite

\begin{tabular}{|c|c|c|c|c|c|c|c|c|}
\hline \multirow[b]{2}{*}{$\begin{array}{l}\text { Nr. } \\
\text { d/o }\end{array}$} & \multirow[b]{2}{*}{$\begin{array}{c}\text { Denumirea băuturii şi termenul de } \\
\text { păstrare }\end{array}$} & \multicolumn{7}{|c|}{ Caracteristicile fizico-chimice } \\
\hline & & 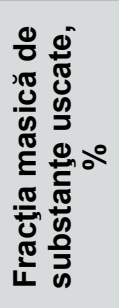 & $\mathrm{pH}$ & 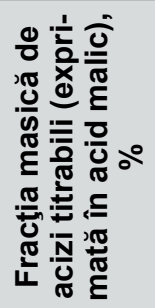 & 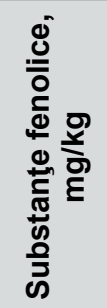 & 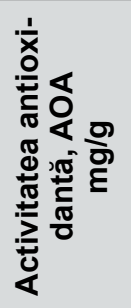 & 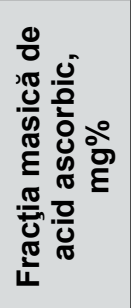 & 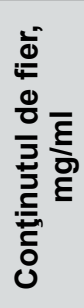 \\
\hline 1. & $\begin{array}{l}\text { Băutură de mere şi vişine limpezită } \\
\text { Mostra de control: } \\
\text { - iniţial } \\
\text { - peste } 6 \text { luni } \\
\text { - peste } 14 \text { luni } \\
\text { - peste } 25 \text { de luni } \\
\text { Gradul de integritate al substanţelor } \\
\text { biologic active, \% }\end{array}$ & $\begin{array}{l}11,5 \\
11,6 \\
11,8 \\
11,7\end{array}$ & $\begin{array}{l}3,30 \\
3,40 \\
3,60 \\
3,35\end{array}$ & $\begin{array}{l}0,31 \\
0,34 \\
0,37 \\
0,35\end{array}$ & $\begin{array}{l}544,0 \\
539,0 \\
524,0 \\
528,0\end{array}$ & $\begin{array}{l}0,12 \\
0,13 \\
0,12 \\
0,07\end{array}$ & $\begin{array}{l}0,63 \\
0,51 \\
0,58 \\
0,46 \\
\\
73,0\end{array}$ & $\begin{array}{l}3,2 \\
3,3 \\
2,7 \\
2,9\end{array}$ \\
\hline 2. & $\begin{array}{l}\text { Mostra fortificată: } \\
\text { - iniţial } \\
\text { - peste } 6 \text { luni } \\
\text { - peste } 14 \text { luni } \\
\text { - peste } 25 \text { de luni } \\
\text { Gradul de integritate al substanţelor } \\
\text { biologic active, \% }\end{array}$ & $\begin{array}{l}11,5 \\
11,6 \\
11,8 \\
11,7\end{array}$ & $\begin{array}{l}3,25 \\
3,35 \\
3,70 \\
3,20\end{array}$ & $\begin{array}{l}0,35 \\
0,36 \\
0,37 \\
0,35\end{array}$ & $\begin{array}{l}620,0 \\
633,0 \\
619,0 \\
589,0\end{array}$ & $\begin{array}{l}0,17 \\
0,19 \\
0,18 \\
0,11\end{array}$ & $\begin{array}{c}13,50 \\
9,90 \\
6,98 \\
6,48\end{array}$ & $\begin{array}{l}15,0 \\
15,4 \\
13,8 \\
14,2\end{array}$ \\
\hline
\end{tabular}

Caracteristicile fizico-chimice ale băuturii de mere limpezite

Tabelul 3

\begin{tabular}{|c|c|c|c|c|c|c|c|c|}
\hline \multirow[b]{2}{*}{$\begin{array}{l}\text { Nr. } \\
\text { d/o }\end{array}$} & \multirow[b]{2}{*}{$\begin{array}{c}\text { Denumirea băuturii şi termenul de } \\
\text { păstrare }\end{array}$} & \multicolumn{7}{|c|}{ Caracteristicile fizico-chimice } \\
\hline & & 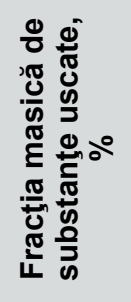 & $\mathrm{pH}$ & 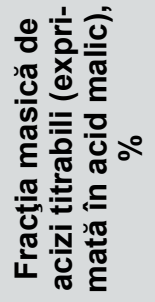 & 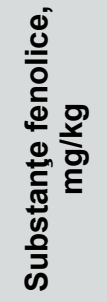 & 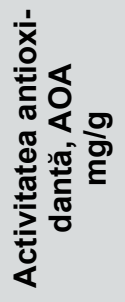 & 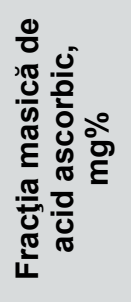 & 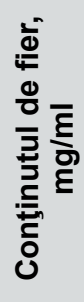 \\
\hline 1. & $\begin{array}{l}\text { Băutură de mere limpezită } \\
\text { Mostra de control: } \\
\text { - iniţial } \\
\text { - peste } 6 \text { luni } \\
\text { - peste } 14 \text { luni } \\
\text { - peste } 25 \text { de luni } \\
\text { Gradul de integritate al substanţelor } \\
\text { biologic active, \% }\end{array}$ & $\begin{array}{l}12,0 \\
12,0 \\
11,8 \\
11,9\end{array}$ & $\begin{array}{l}3,30 \\
3,40 \\
3,30 \\
3,25\end{array}$ & $\begin{array}{l}0,28 \\
0,30 \\
0,30 \\
0,31\end{array}$ & $\begin{array}{l}367,0 \\
312,0 \\
335,0 \\
344,0\end{array}$ & $\begin{array}{l}0,18 \\
0,10 \\
0,09 \\
0,05 \\
\\
\\
28,0\end{array}$ & $\begin{array}{l}0,35 \\
0,30 \\
0,31 \\
0,28 \\
\\
\\
80,0 \\
\end{array}$ & $\begin{array}{l}1,5 \\
1,7 \\
1,9 \\
1,6\end{array}$ \\
\hline 2. & $\begin{array}{l}\text { Mostra fortificată: } \\
\text { - iniţial } \\
\text { - peste } 6 \text { luni } \\
\text { - peste } 14 \text { luni } \\
\text { - peste } 25 \text { de luni } \\
\text { Gradul de integritate al substanţelor } \\
\text { biologic active, \% }\end{array}$ & $\begin{array}{l}12,0 \\
12,0 \\
12,0 \\
11,7\end{array}$ & $\begin{array}{l}3,30 \\
3,35 \\
3,30 \\
3,25\end{array}$ & $\begin{array}{l}0,31 \\
0,33 \\
0,31 \\
0,31\end{array}$ & $\begin{array}{l}665,0 \\
591,0 \\
631,0 \\
512,0\end{array}$ & $\begin{array}{l}0,58 \\
0,26 \\
0,24 \\
0,15\end{array}$ & $\begin{array}{l}29,0 \\
25,3 \\
18,9 \\
14,2\end{array}$ & $\begin{array}{l}20,0 \\
19,9 \\
19,6 \\
19,2\end{array}$ \\
\hline
\end{tabular}


Denumirea băuturii şi termenul de păstrare

Caracteristicile fizico-chimice ale băuturii de mere şi caise nelimpezite

\begin{tabular}{|c|c|c|c|c|c|c|c|c|}
\hline \multirow[b]{2}{*}{$\begin{array}{l}\mathrm{Nr} . \\
\mathrm{d} / \mathrm{o}\end{array}$} & \multirow[b]{2}{*}{$\begin{array}{l}\text { Denumirea băuturii şi termenul } \\
\text { de păstrare }\end{array}$} & \multicolumn{7}{|c|}{ Caracteristicile fizico-chimice } \\
\hline & & 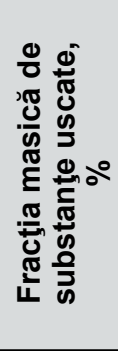 & pH & 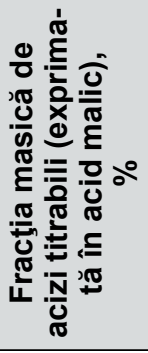 & 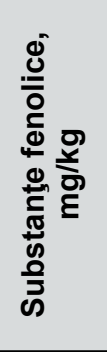 & 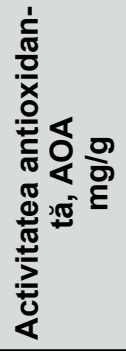 & 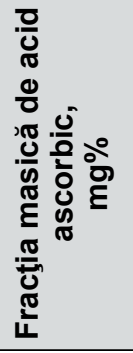 & 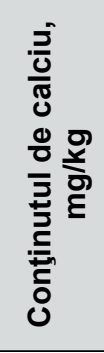 \\
\hline 1. & $\begin{array}{l}\text { Băutură de mere şi caise nelim- } \\
\text { pezită } \\
\text { Mostra de control: } \\
\text { - iniţial } \\
\text { - peste } 6 \text { luni } \\
\text { - peste } 14 \text { luni } \\
\text { - peste } 25 \text { de luni } \\
\text { Gradul de integritate al substan- } \\
\text { ţelor biologic active, \% }\end{array}$ & $\begin{array}{l}13,3 \\
13,5 \\
13,0 \\
13,3\end{array}$ & $\begin{array}{l}3,30 \\
3,45 \\
3,50 \\
3,45\end{array}$ & $\begin{array}{l}0,30 \\
0,26 \\
0,26 \\
0,30\end{array}$ & $\begin{array}{l}376,0 \\
337,0 \\
322,0 \\
302,0\end{array}$ & $\begin{array}{l}0,10 \\
0,10 \\
0,09 \\
0,05 \\
50,0\end{array}$ & $\begin{array}{l}0,380 \\
0,225 \\
0,181 \\
0,126 \\
\\
33,0 \\
\end{array}$ & $\begin{array}{l}67,0 \\
\text { idem } \\
\text { idem } \\
\text { idem }\end{array}$ \\
\hline 2. & $\begin{array}{l}\text { Mostra fortificată: } \\
\text { - iniţial } \\
\text { - peste } 6 \text { luni } \\
\text { - peste } 14 \text { luni } \\
\text { - peste } 25 \text { de luni } \\
\text { Gradul de integritate al substan- } \\
\text { ţelor biologic active, \% }\end{array}$ & $\begin{array}{l}13,5 \\
13,6 \\
13,5 \\
13,3\end{array}$ & $\begin{array}{l}3,60 \\
3,65 \\
3,70 \\
3,75\end{array}$ & $\begin{array}{l}0,30 \\
0,28 \\
0,26 \\
0,29\end{array}$ & $\begin{array}{l}358,0 \\
346,0 \\
326,0 \\
312,0\end{array}$ & $\begin{array}{l}0,11 \\
0,10 \\
0,10 \\
0,06 \\
54,0\end{array}$ & $\begin{array}{l}0,380 \\
0,214 \\
0,163 \\
0,136 \\
36,0\end{array}$ & $\begin{array}{l}656,0 \\
\text { idem } \\
\text { idem } \\
\text { idem }\end{array}$ \\
\hline
\end{tabular}

diata sterilizare conform regimului unde temperatura sterilizării proprii nu depăşeşte $85^{\circ} \mathrm{C}$. Sterilizarea pentru borcanele III-66-350 s-a realizat conform regimului:

$$
\underline{6-12-20}
$$$$
85 .
$$

Compuşii calciului şi ai fierului au fost introduşi în băutură prin dizolvarea într-o cantitate mică de băutură sustrasă din masa totală după încălzirea ei, începând cu temperatura de $45^{\circ} \mathrm{C}$, până la introducerea vitaminei $\mathrm{C}$.

\section{REZULTATE ȘI DISCUȚII}

Caracteristicile fizico-chimice ale mostrelor de băuturi au fost cercetate la momentul fabricării şi pe durata de păstrare timp de 25 de luni. Rezultatele cercetării caracteristicilor fizico-chimice ale mostrelor de băuturi şi modificarea conţinutului de fortificanţi - fier, acid ascorbic şi calciu, în procesul tehnologic şi pe durata păstrării sunt prezentate în tabelele 2, 3 şi 4.

Aprecierea organoleptică a băuturilor a demonstrat că adăugarea fortificanţilor nu schimbă gustul şi mirosul acestora. Băuturile sunt plăcute, cu gust şi aromă ale fructelor utilizate la fabricarea mostrelor.

Pentru băuturile fortificate cu fier şi acid ascorbic pierderile acidului ascorbic în procesul sterilizării ating $19 \%$, după 4 luni de păstrare pierderile acidului ascorbic constituie 35-37\%, atât în mostrele de control cu conţinut nativ de acid ascorbic, cât şi în mostrele forti- ficate cu $16 \%$ de fier din DZR şi $40 \%$ de acid ascorbic din DZR (luând în considerare conţinutul nativ). După 6 luni de păstrare pierderile acidului ascorbic se măresc, comparativ cu perioada de 4 luni, cu $1-4 \%$.

La fortificarea băuturilor cu aceiaşi fortificanţi, dar în cantităţi mărite $-30 \%$ Fe din DZR şi $85 \%$ de acid ascorbic din DZR - în primele 4 luni de păstrare pierderile acidului ascorbic au crescut până la $58 \%$, iar în următoarele 2 luni pierderile în plus n-au depăşit 1\%, ceea ce demonstrează încetinirea distrugerii acidului ascorbic. Caracteristicile organoleptice ale mostrelor pe durata păstrării nu se schimbă, gust şi miros străin nu se depistează.

Conţinutul de $\mathrm{Fe}$ şi Ca se determină fără dificultăți şi nu influenţează caracteristicile organoleptice, cantitatea lor se află la nivelul valorilor iniţiale.

După 25 de luni de păstrare integritatea acidului ascorbic în băutura de vişine cu mere şi în băutura de mere nefortificată a constituit 73 şi $80 \%$ corespunzător, în produsele analogice fortificate (cu fier şi acid ascorbic) integritatea acidului ascorbic este mai mică şi a constituit 48 şi $49 \%$ corespunzător.

În băutura de mere şi caise (fortificată cu calciu) integritatea acidului ascorbic este cea mai mică - 33-36\%, dar este mic şi conţinutul iniţial al acestuia în băutură.

Datele din tabelele 2 şi 3 indică că conţinutul de substanţe fenolice în băuturile de mere şi vişine şi băuturile de mere fortificate cu acid ascorbic şi fier este mai mare decât cel din mostrele de control, şi este de menţionat faptul că această diferenţă se măreşte odată cu 
mărirea cantităţi de acid ascorbic adăugat. Fenomenul se explică prin faptul că reagentul Folin-Ciocalteu, pe lângă substanţele fenolice, poate intra în reacţie cu acidul ascorbic şi zaharurile reducătoare.

Conţinutul de fier şi calciu în mostrele fortificate pe durata păstrării a 25 de luni practic nu s-a modificat. Este foarte important şi faptul că fierul nu şi-a schimbat valenţa, rămânând la valenţa (II) sub care este asimilată de organismul uman.

\section{CONCLUZII}

Pentru fabricarea băuturilor cu conţinut garantat de vitamine şi minerale în produsul finit, stabil pe durata păstrării, s-a experimentat tehnologia de introducere a calciului, fierului şi vitaminei $\mathrm{C}$ pe trei loturi de băuturi.

S-a ales sortimentul de băuturi pe baza materiei prime de fructe autohtone şi au fost fabricate băuturi: limpezite pe bază de sucuri fortificate cu fier şi vitamina C şi nelimpezite cu miez fortificate cu calciu.

S-au selectat cei mai potriviți compuşi ai calciului şi ai fierului pentru fortificarea produselor sub formă lichidă şi dozele lor.

Cantitatea de fier, calciu și vitamina $\mathrm{C}$ a fost calculată în aşa mod, încât produsul finit să conţină $15 \%$ din doza zilnică recomandată de fier, $30 \%$ din doza zilnică recomandată de vitamina $\mathrm{C}, 15 \%$ din doza zilnică recomandată de calciu, corespunzător în băuturile fortificate cu acestea.

Analiza caracteristicilor fizico-chimice, organoleptice şi a gradului de integritate al vitaminei $C$ şi substanţelor minerale introduse în băuturi a demonstrat corectitudinea tehnologiei experimentate, inclusiv a etapelor tehnologice de introducere a fortificanţilor şi regimurilor termice.

Conţinutul de fier şi de calciu în mostrele de băuturi nu s-a modificat pe durata păstrării în decurs de 25 de luni. Conţinutul acidului ascorbic peste 25 de luni de păstrare s-a redus de 2 ori.
Notă: Cercetările au fost efectuate în cadrul proiectului „Program de Stat” 15.817.05.03A „Dezvoltarea tehnologiilor de procesare a materiei prime agroalimentare indigene în asigurarea calităţii şi siguranţei alimentelor".

\section{BIBLIOGRAFIE}

1. Programul Naţional de profilaxie şi combatere a diabetului zaharat pentru anii 2011-2015, aprobat prin Hotărârea Guvernului nr. 549 din 21.07.2011, anexa 1. Monitorul Oficial al Republicii Moldova din 29 iulie 2011, nr. 122-127.

2. Hotărârea Guvernului nr. 596 din 03.08.2011 „Cu privire la aprobarea unor măsuri de eradicare a tulburărilor prin deficit de iod". Monitorul Oficial al Republicii Moldova din 12 august 2011, nr.131-133.

3. Reglementarea Tehnică „Sucuri şi anumite produse similare destinate consumului uman", aprobată prin Hotărârea Guvernului nr. 1111 din 06.12.2010. Monitorul Oficial al Republicii Moldova din 17.12.2010, nr. 247-251.

4. SM 168:1997 „Băuturi de fructe şi pomuşoare. Condiţii tehnice".

5. Regulamentul sanitar privind suplimentele alimentare, aprobat prin Hotărârea Guvernului nr. 538 din 02.09.2009. Monitorul Oficial al Republicii Moldova din 8 septembrie 2009, nr.138-139.

RECENZIE ŞTIINȚIFICĂ - Larisa IUȘAN, doctor în știinţe tehnice.

Materialul a fost prezentat la 02.06.2021. 